\title{
Research on Static Compression Test of Polyurethane Foam/Honeycomb Paperboard Composite Material
}

\author{
Wang $\mathrm{Ju}^{*}{ }^{* 1,2,3}$, Liang Jifeng ${ }^{1,2,3}$ and Lv Lei ${ }^{1,2,3}$ \\ ${ }^{I}$ China University of Mining and Technology, Xuzhou, Jiangsu, 221000, China \\ ${ }^{2}$ School of Transportation, Wuhan University of Technology, Wuhan, Hubei, 430000, China \\ ${ }^{3}$ Air Force Logistics College, Xuzhou, Jiangsu, 221000, China
}

\begin{abstract}
To study the mechanical behavior and energy absorption ability of polyurethane foam/honeycomb paperboard composite material under the static compression test.

The static compression tests of polyurethane foam/honeycomb paperboard composite material are conducted by electronic universal testing machine. The mechanical behavior under the condition of static compression and the factors influencing the composite materials' static cushioning properties were analyzed. Then, a comparison was made based on the energy absorption ability between composite materials and simple materials.

The yield stress, strength and other indicators of foam/honeycomb paperboard have doubled the growth after filling polyurethane. The aperture size is the main influencing factor affecting the static cushioning properties of composite material.
\end{abstract}

The energy absorption amount of composite materials is about 1.85 times than the total energy of two simple materials.

Keywords: Energy absorption appraisal, polyurethane foam/Honeycomb paperboard, static compression test.

\section{INTRODUCTION}

As an important method of material supply, airdrop is playing an increasingly important role in the activities of disaster rescue. At the end phase of its decline close to the ground, landing loading has bad impacts on airdropped supply and equipment $[1,2]$. Therefore, the design and choice of energy-absorption materials to reduce the loading impacts and energy absorption of the airdropped packages, has become an increasingly important research area [3-8]. Foam and honeycomb-structure paperboard are widely used in today's protective packaging materials [9-12]. With a lightweight bionic structure, honeycomb paperboard has better application performance. It has two layers of tissue papers and an intermediate paper honeycomb core, which serves as an adhesive bond between the two layers of paper tissues, forming a honeycomb sandwich structure [13-15]. In this paper, the polyurethane foam is filled into honeycomb paperboard. As a revolutionary cushion material, it has a composite structure to improve energy absorption and environmental adaptability, which has important scientific and engineering significance.

*Address correspondence to this author at the China University of Mining and Technology, Xuzhou, Jiangsu, 221000, China; Tel: 15952160680; E-mail: wangju1021@foxmail.com

\section{EXPERIMENT MATERIALS}

\subsection{Honeycomb Paperboard}

Honeycomb paperboard materials are obtained from Shanghai Huanchang Packaging Materials Co., Ltd., including three size categories: $6 \mathrm{~mm}$ aperture, the thickness of $15 \mathrm{~mm}$; aperture of $8 \mathrm{~mm}$, thickness $20 \mathrm{~mm} ; 10 \mathrm{~mm}$ aperture, thickness $20 \mathrm{~mm}$, respectively. Tissue paper weight is $220 \mathrm{~g} / \mathrm{m}^{2} \sim 260 \mathrm{~g} / \mathrm{m}^{2}$, weight of the core paper is $140 \mathrm{~g} /$ $\mathrm{m}^{2}$, coating weight is $120 \mathrm{~g} / \mathrm{m}^{2}$, a thickness of the cellular tissues is $0.5 \mathrm{~mm}$, and thickness of single core paper is 0.22 $\mathrm{mm}$, which are shown in Fig. (1).

\subsection{Polyurethane Material}

Polyurethane foam is obtained from Jinan Zhuogao Building Material Co.; and pure polyurethane specimens were cut into $15 \mathrm{~mm}$ and $20 \mathrm{~mm}$ thickness.

\subsection{Preparation of Polyurethane Honeycomb Paperboard}

Honeycomb core is first placed on top of a sieve, and then just the semi-solid polyurethane foam are uniformly sprayed onto honeycomb core surface and pressed down with a flat tool, so that the foam would be evenly distributed throughout the honeycomb core. Wait for ten minutes until a layer is formed and then cut it to level-up with a knife. 


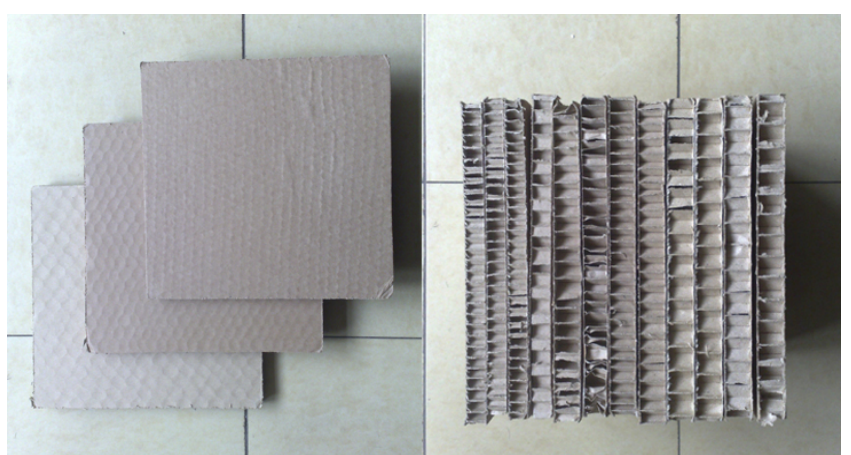

Fig. (1) The honeycomb paperboard materials of three different aperture size and thickness.

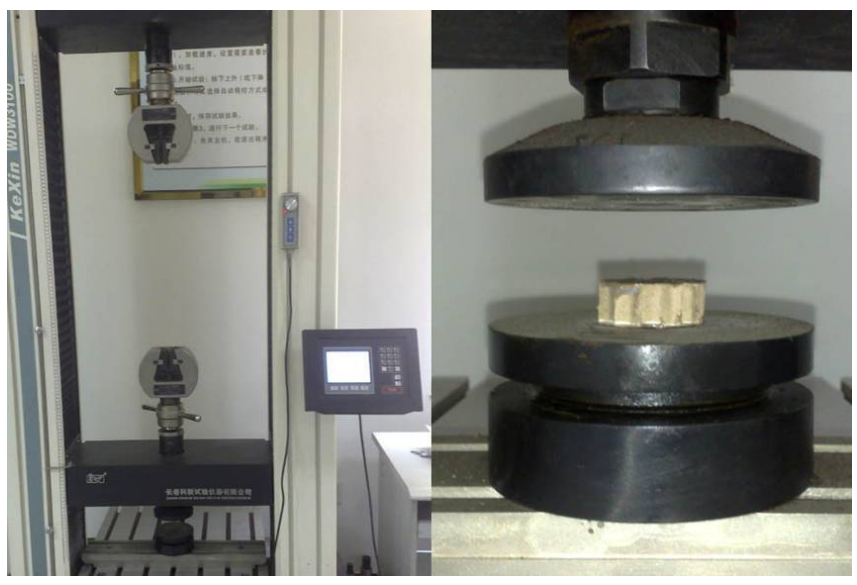

Fig. (2) Universal testing machine (left) and the amplification figure of compression space (right) (The Manufacturer Name: Shanghai Yihuan Instrument Co., Ltd. Address: Shanghai Jiading District Huangdu Industrial Park).

\section{EXPERIMENTAL DESIGN}

Experiments are conducted on the electronic universal testing machine produced by Shanghai Yihuan Instrument Co., Ltd., with machine specifications $100 \mathrm{kN}$ and a loading speed of $10 \mathrm{~mm} / \mathrm{min}$ as shown in Fig. (2). In order to eliminate the influence of accidental factors to obtain a more accurate test data, three test pieces are produced in each experiment to obtain the average. 15 data points are sampled every second, in order to capture the peak of force. The numbers and specifications of each specimen are shown in Table 1. Note that the specifications of the data are the average dimension of the three specimens.

\section{STATIC TEST RESULT}

\subsection{Comparison of Statics Performance of Honeycomb Paperboard Before and After Polyurethane Filling}

The original specimen force-displacement waveform curves of No. 1 and No. 6 specimens are shown in Fig. (3). A slight increase in the diameter of the specimens is due to the filling effect (38 $\mathrm{mm}$ before filling; $44 \mathrm{~mm}$ after filling). In order to eliminate this effect, the original force, i.e. the displacement curve of the stress, is transformed into the stress-strain curve, as shown in Fig. (4).

From Figs. $(\mathbf{3}, \mathbf{4})$, it can be seen that:

(1) The yield stress, strength and other indicators of the honeycomb paperboard have grown exponentially after the polyurethane filling;

(2) At a displacement of $0.4579 \mathrm{~mm}$, the pressure of honeycomb filling reaches the first peak of $495 \mathrm{~N}$, corresponding to a strain of 0.0305 and a stress of $0.4364 \mathrm{MPa}$, when the elastic phase is coming to an end. At this point, the pressure of the honeycomb filling reaches $119.25 \mathrm{~N}$, corresponding to a strain of 0.0305 and a stress of only $0.0784 \mathrm{MPa}$. This time honeycomb composite polyurethane elastic stage has only started.

(3) When the displacement reaches $1.9871 \mathrm{~mm}$, the pressure of the polyurethane-filled honeycomb cardboard reaches the first peak of $824.5 \mathrm{~N}$. At this point, the corresponding strain reaches 0.1325 , the stress, $0.5422 \mathrm{MPa}$, and the yield (stress oscillation) stage is close to end. At this point, the pressure of the unfilled honeycomb material is $254 \mathrm{~N}$, corresponding to a strain of 0.1325 and stress of only $0.2240 \mathrm{MPa}$, which is going to the end stage of polyurethane composites honeycomb marked by instability.

(4) Comparing the calculated modulus of elasticity of the material before and after filling, the number is 14.3082 $\mathrm{MPa}$ and 4.0921 $\mathrm{MPa}$ respectively. It may be gathered that the composite goes straight to the

Table 1. The specimen number and its specifications

\begin{tabular}{|c|c|c|c|}
\hline NO. & Specimen Types & Aperture/mm & Dhickness/mm \\
\hline \hline 1 & Pure honeycomb paperboard & 6 & 15 \\
\hline 2 & Pure honeycomb paperboard & 8 & 20 \\
\hline 3 & Pure honeycomb paperboard & 10 & 20 \\
\hline 4 & Pure polyurethane & None & 15 \\
\hline 5 & Pure polyurethane & None & 20 \\
\hline 6 & Polyurethane honeycomb paperboard composite materials & 6 & 15 \\
\hline 7 & Polyurethane honeycomb paperboard composite materials & 48 & 40 \\
\hline 8 & Polyurethane honeycomb paperboard composite materials & 48 & 20 \\
\hline
\end{tabular}




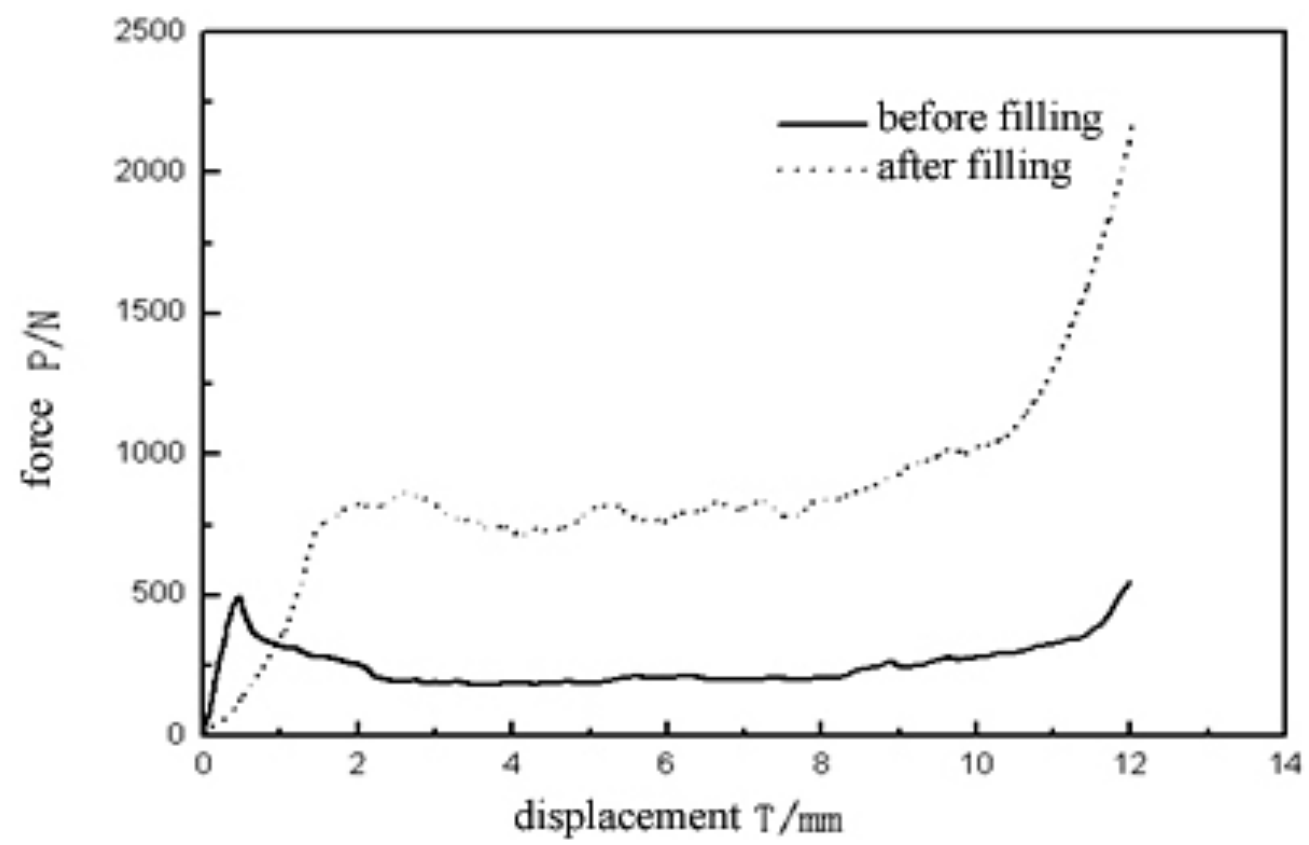

Fig. (3) The initial wave of aperture $6 \mathrm{~mm}$ and thickness $15 \mathrm{~mm}$ honeycomb paperboard before and after filling with polyurethane,

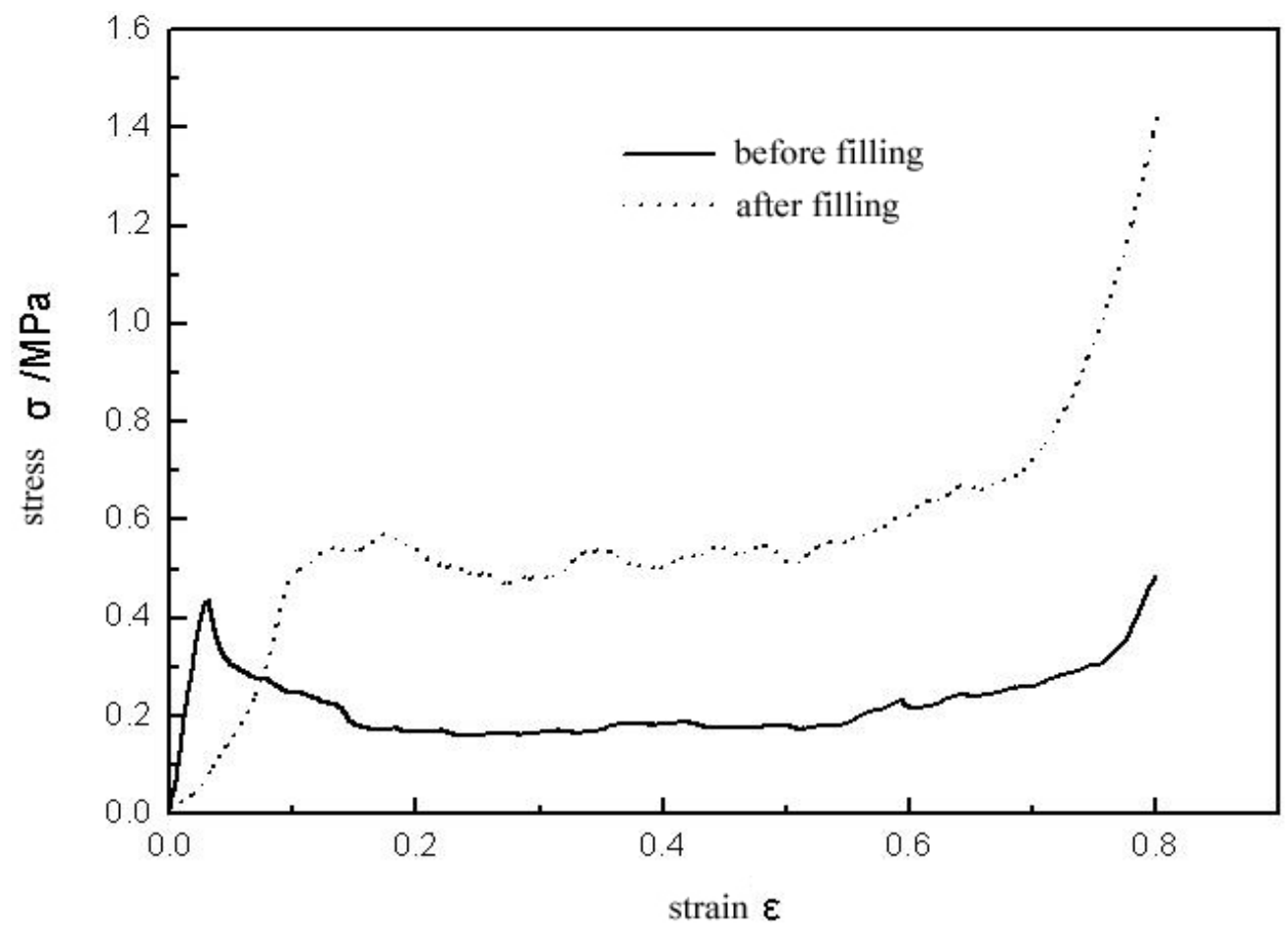

Fig. (4) The stress-strain curve of aperture $6 \mathrm{~mm}$ and thickness $15 \mathrm{~mm}$ honeycomb paperboard before and after filling with polyurethane.

yielding stage without buckling, or the surface of the composite material remains part of polyurethane.

By Figs. (2-4), it can be seen that the polyurethane padding has enhanced the extension of the elastic stage of honeycomb board, making the instability phase no longer apparent. Thus, the compression and deformation processes changed from the original four stages into three stages, or to some extent, polyurethane, which is completely filled, enhances the solid features of Honeycomb, and partially reduces its gas phase characteristics.

\subsection{Factors Affecting the Static Mechanical Properties}

\subsubsection{Analysis of the Impact of Pore Size on the Static Mechanical Properties of Pure Honeycomb Materials}

The strain curves of the honeycomb material specimen with an aperture of $6 \mathrm{~mm}, 8 \mathrm{~mm}$ and $10 \mathrm{~mm}$ is shown in Fig. (5), which shows that the compressible strength and yield strength of the honeycomb material are decreased with increased aperture, and the level of energy absorption declines correspondingly. This analysis shows that the 


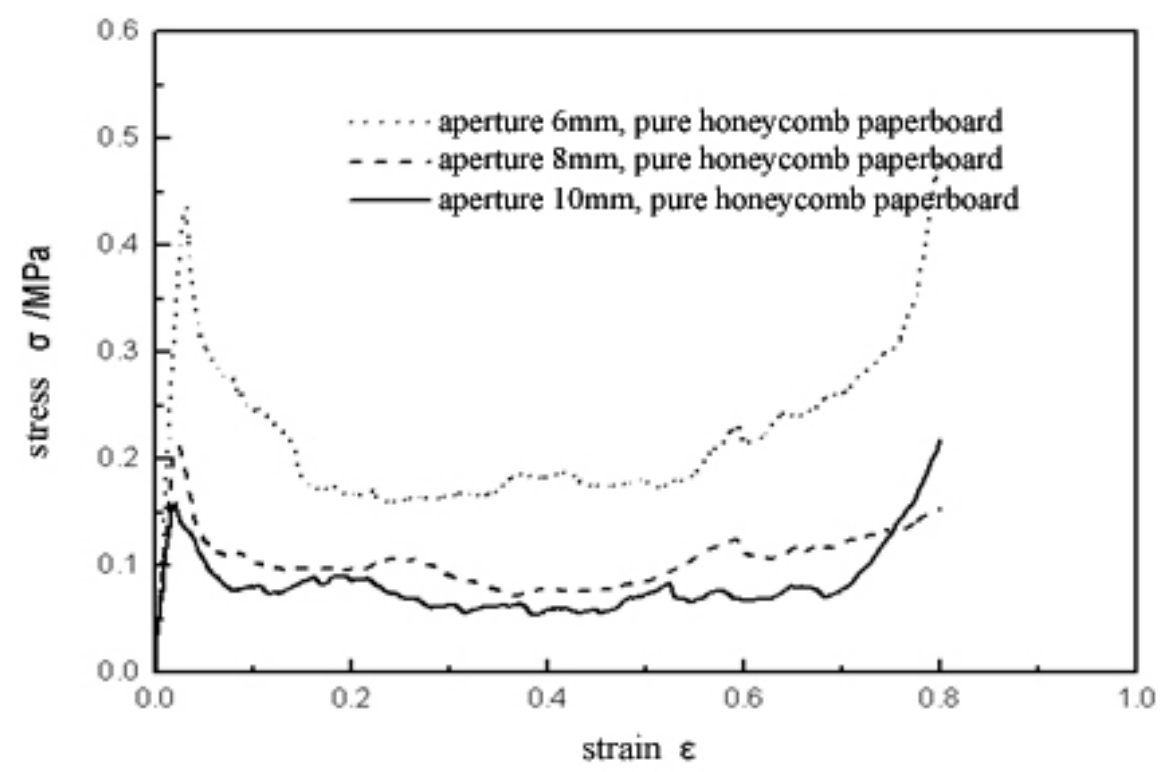

Fig. (5) The stress-strain curves of pure honeycomb paperboard with three kinds of apertures.

aperture has a significant impact on the mechanical properties.

\subsubsection{Analysis of the Impact of Thickness on the Simple Static Analysis of Polyurethane Materials}

The stress-strain curves of the polyurethane specimens with a thickness of $15 \mathrm{~mm}$ and $20 \mathrm{~mm}$, are shown in Fig. (6). It proves that the thickness has a certain impact on the stressstrain curve of the specimen. With the effective work of the previous segment in compaction point, the compressible yield and the level of energy absorption of polyurethane materials both increase with the thickness, but this effect is not obvious. When the strain is greater than 0.64 , close to the point of compaction, the specimen thickness of $15 \mathrm{~mm}$ stress- strain begins to exceed $20 \mathrm{~mm}$ specimen and the first to enter the compaction phase.

\subsubsection{Analysis of the Impact of Pore Size on the Static Performance of Composite Material}

The stress-strain curves of the composite material with an aperture of $6 \mathrm{~mm}, 8 \mathrm{~mm}$ and $10 \mathrm{~mm}$, are shown in Fig. (7), which shows that the strength and yield of the composite material are decreased with the pore size, while the level of energy absorption decreases correspondingly.

\subsubsection{Analysis of the Thickness Impact on the Static Buffer Performance of the Composite Material}

The stress-strain curves of the specimens with different apertures of $6 \mathrm{~mm}, 15 \mathrm{~mm}$ and $20 \mathrm{~mm}$, are shown in Fig. (8), which indicates that the cushioning material thickness increases while the yield strength decreases, but this effect was not significant in the yield phase.

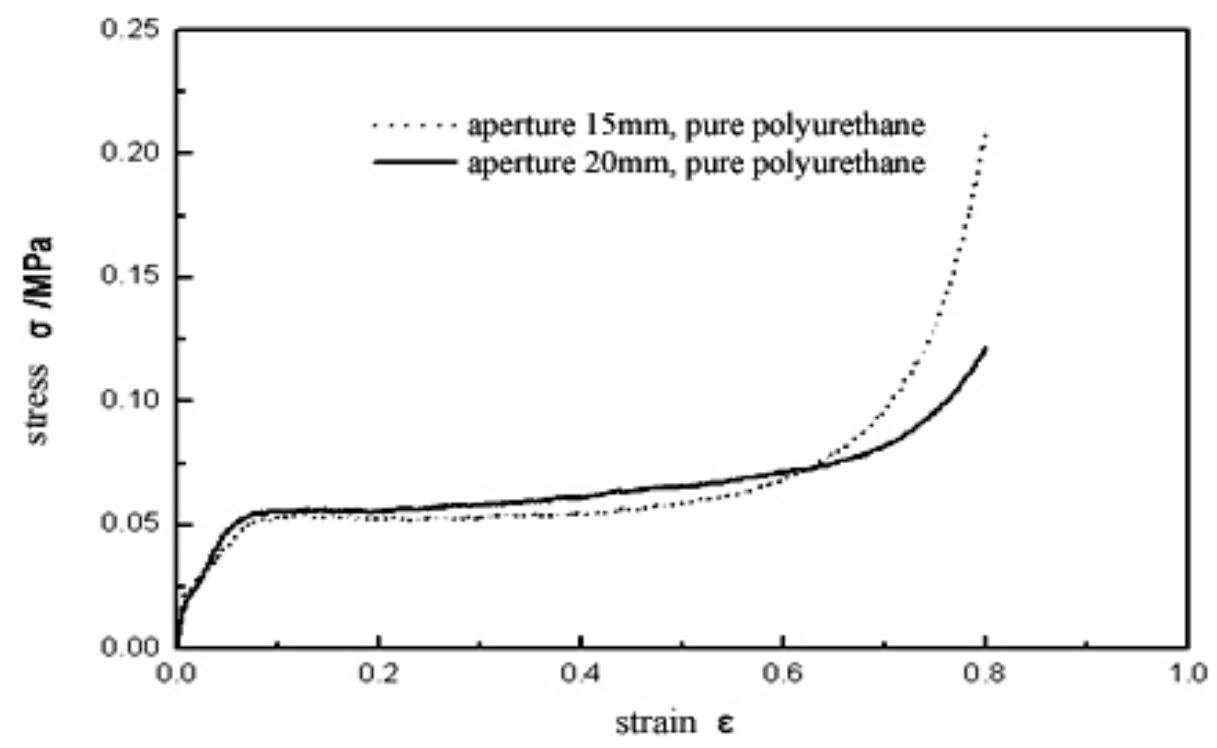

Fig. (6) The stress-strain curve of pure polyurethane specimen of the $15 \mathrm{~mm}$ and $20 \mathrm{~mm}$ thickness. 


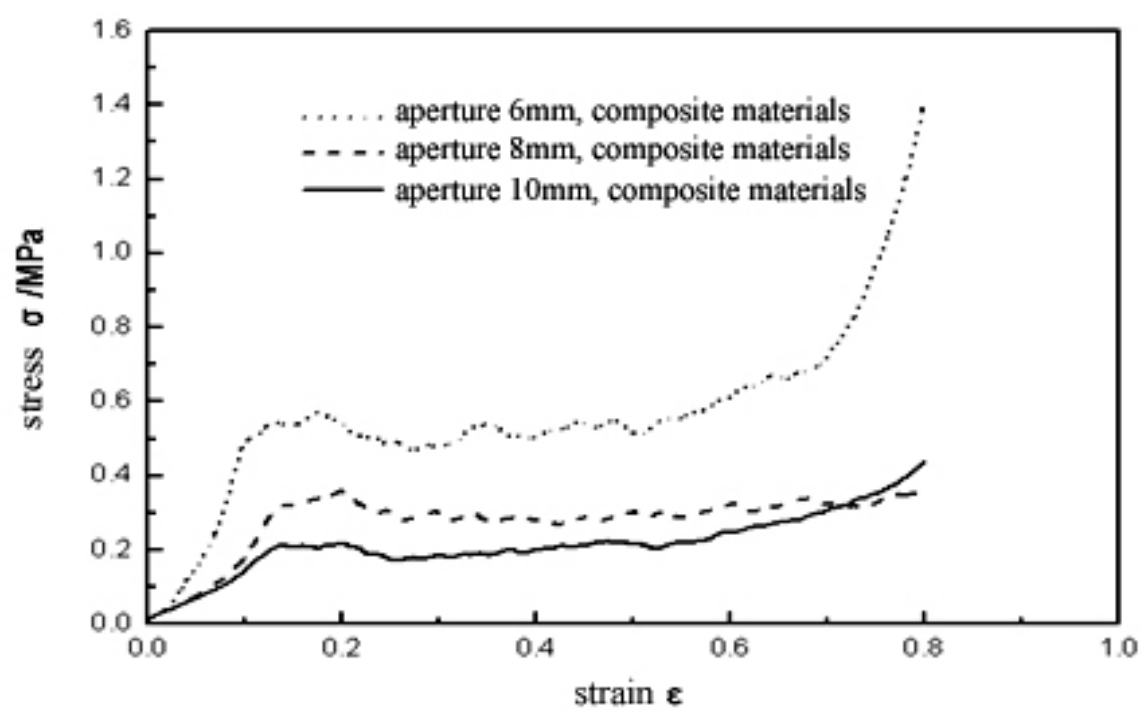

Fig. (7) The stress-strain curve of composite material with three different pore size composite materials.

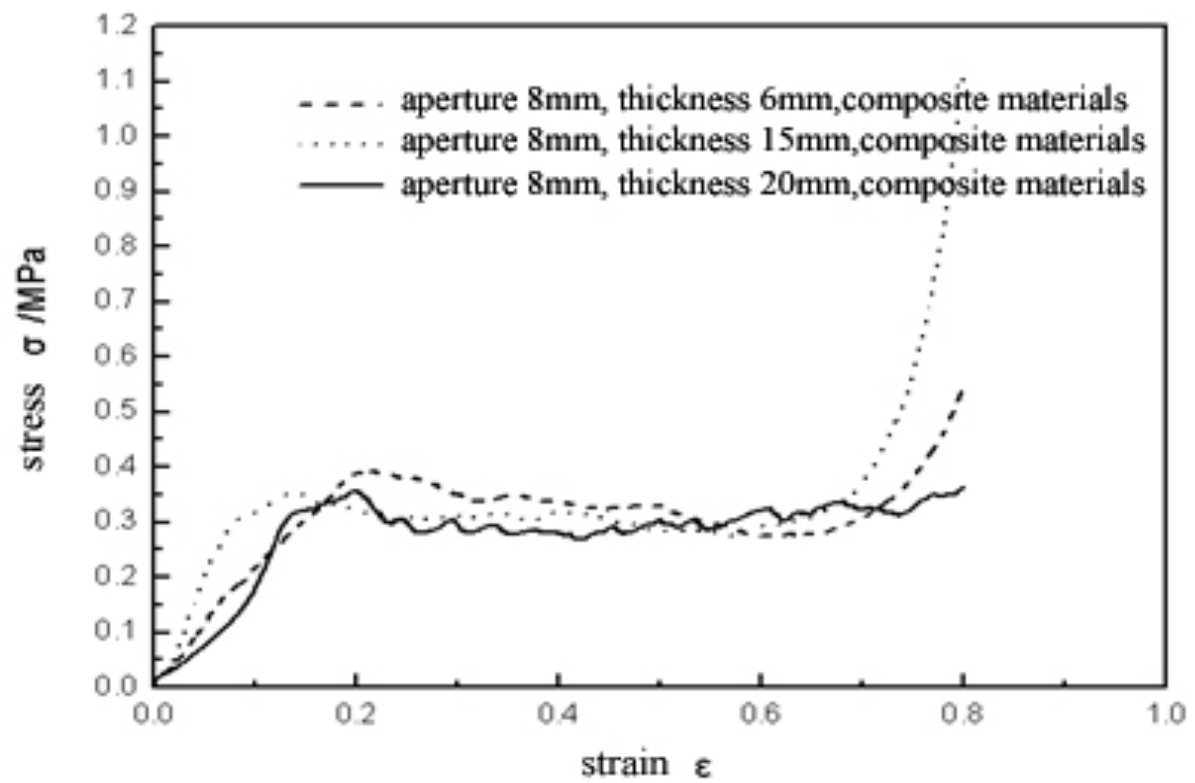

Fig. (8) The stress-strain curve of three kinds of composite materials with $8 \mathrm{~mm}$ aperture.

\section{COMPARISON BETWEEN THE LEVELS OF ENERGY ABSORPTION OF THE COMPOSITE AND SIMPLE HONEYCOMB MATERIALS}

Take a polyurethane Honeycomb composite with $6 \mathrm{~mm}$ aperture as example, the composite material was analyzed and compared with two kinds of simple static energy absorption composite materials. Fig. (9) is a stress composite with three materials (on the $1^{\text {st }}$, the $4^{\text {th }}$ and the $6^{\text {th }}$ specimens) stress-strain curve. Integral research from beginning of compression to the end of yield phase, obtained a composite material under the package curve area of the approximately $0.349 \mathrm{MJ} / \mathrm{m}^{3}(10.5 \mathrm{~mm}$ deformation takes place as the end point of the yield); pure Honeycomb under the package area of approximately $0.152 \mathrm{MJ} / \mathrm{m}^{3}$ (11 $\mathrm{mm}$ deformation takes place as the end point of the yield); and so pure polyurethane bag under an area of approximately $0.037 \mathrm{MJ} / \mathrm{m}^{3}(10 \mathrm{~mm}$ deformation takes place as the end point of the yield). It has been concluded that the unit volume of the three materials (composite material, pure polyurethane and pure Honeycomb) absorb energy approximately $0.349 \mathrm{MJ} / \mathrm{m}^{3}, 0.152 \mathrm{MJ} / \mathrm{m}^{3}$ and $0.037 \mathrm{MJ} / \mathrm{m}^{3}$ respectively.

The total energy absorption of the first two materials before composite is $0.189 \mathrm{MJ} / \mathrm{m}^{3}$. The energy absorption after composite is $0.349 \mathrm{MJ} / \mathrm{m}^{3}$, which shows that the energy absorption of the composite material is 1.85 times higher than the sum of energy absorption of the other two materials before composite. The energy absorption of composite materials has been greatly improved compared to the individual materials. From the structural point of view, it is not only because the polyurethanes absorbed part of energy while deforming the core of paper honeycomb during the 
process of compression, but also it enhanced the bending resistance of the honeycomb core and the suction energy capacity through the pressure on the horizon of the walls of the honeycomb core. The energy absorption mentioned above is only for the yield point. During the whole stage of compression process, energy absorption values of every points change every moment. Therefore, it is necessary to create an absorption-strain curve for the new materials and conduct a comprehensive analysis on the whole process of compression energy.

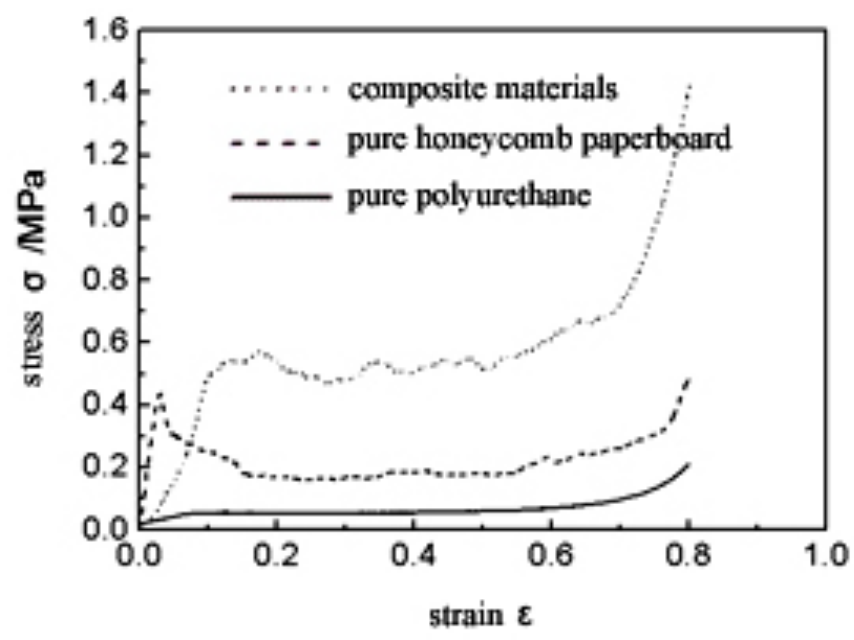

Fig. (9) The stress-strain curve of three kinds of materials.

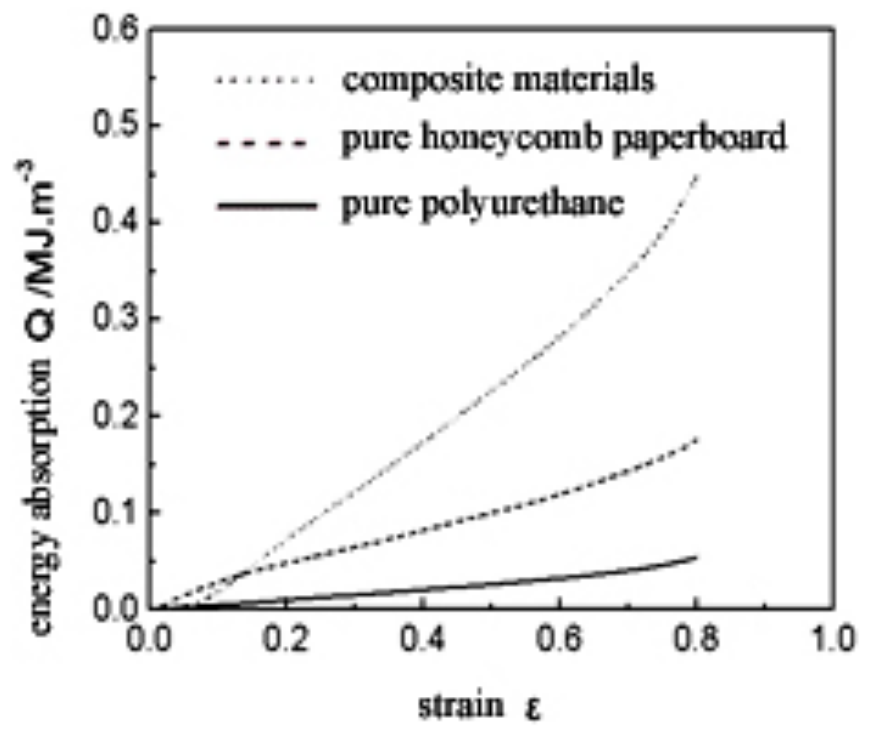

Fig. (10) The energy absorbing strain curve of three kinds of materials.

Fig. (10) shows a composite of $6 \mathrm{~mm}$ aperture, pure and simple Honeycomb polyurethane energy absorption-strain $(\mathrm{Q}-\varepsilon)$ curve, which shows that most of the strains fall within the range of 0.133 to 0.8 , that is the composite material's energy absorbing levels were significantly higher than the other two kinds of simple materials. Because of energy-absorbing protective type buffering stage for major work yield stage, Honeycomb cushioning properties of polyurethane composites were significantly higher than the two pure materials. From the point of view of energy absorption of this index, honeycomb reinforced polyurethane material is indeed an excellent energy absorbing material.

\section{CONCLUSION}

In this paper, honeycomb composite is prepared by polyurethane filling, and the property of pure honeycomb is improved as shown by experiments. Static tests suggested that composites are a better material as proved through the analysis of the main factors and evaluation of energy absorption capacity. The main conclusions are:

Variable analysis: pore size is an important factor affecting the performance of the composite static buffer. With the decrease of honeycomb core pore size, the yield strength and elastic limit of composite enhanced, the stress-strain curve amplitude increased significantly, but the yield strain interval corresponding with the yield stage basically remained unchanged; influence of the thickness of the composite static buffer performance is not very obvious, and hence is uncertain.

Energy absorption areas: After filling composite polyurethane foam into honeycomb, its energy absorption characteristics have been greatly improved in the static compression test, that is the energy absorption of composite materials is 1.85 times higher than the sum of two other samples.

\section{CONFLICT OF INTEREST}

The authors confirm that this article content has no conflict of interest.

\section{ACKNOWLEDGEMENTS}

Project is supported by the National Natural Science Foundation of China (Grant No.0504014).

\section{REFERENCES}

[1] Tan J, Han X, Liu X. The numerical simulation analysis and improvement of a certain vehicles dropped landing. Packaging Eng. 2010; 31(1): 57-61.

[2] Yu P, Wang Z. Advance in study on energy-absorbing property of paper-based cushion packing materials. Vibration and shock 2010; 29(5): 40-45.

[3] Zhang F, Liu Y, Qi M. Influence of aluminum foam-polyurethane composite thickness on its cushioning performance. Packaging Eng. 2011; 32(9): 24-26, 53.

[4] Chen DH, Ozaki S. Analysis of in-plane elastic modulus for a hexagonal honeycomb core: Effect of core height and proposed analytical method. Composite Structures 2009; 88: 17-25

[5] Zhu HX, Hobdell J.R., Windle AH. Effects of cell irregularity on the elastic properties of 2D Voronoi honeycombs. J Mech Phys Solids 2001; 49(4): 857-70.

[6] Hiroaki N, Tadaharu A, Wakako A. n-plane impact behavior of honeycomb structures randomly filled with rigid inclusions. International Journal of Impact Eng. 2009; 36: 73-80.

[7] Paul A, Ramamurty U. Strain rate sensitivity of a Closed-cell aluminum foam. Mat Sci Eng. A 2000; 281: 1-7.

[8] Baumeister J, Banhart J. Aluminum Foams for Transport Industry. Mat Design 1997; 18(46): 217-20.

[9] Qi M, Zhang J, Yang W, Zhang F. Research on shock cushioning performance of foamed Aluminum-polyurethane composite structure. Packaging Eng. 2010; 31(19): 6-9.

[10] Yin H, Wen G, Ma C, Han W. Optimization design of cushion instrument of honeycomb structure. Chinese Mechanical Eng. 2011; 22(10): 1153-58.

[11] Wu Y, Wu D, Lin G, et al. A simplified calculation method for the bearing capacity of hexagon-hole castellated beamed. Engineering, 2009; 41(2): 5-8. 
[12] Chen M, Chen D. A Study on in-plane equivalent elastic parameters of right hexagonal honeycomb core. J East China Jiaotong University, 2010; 27(5): 1-4.

[13] Guo Y, Xin C, Xu W. Finite element analysis on flat crush property of honeycomb paperboard structure. Packaging Eng. 2009; 30(1): 34-35.
[14] Yan L, Xie Y. Dynamic cushioning properties of combination of honeycomb paperboard and EPE. Packaging Eng. 2010; 31(19): 27-31.

[15] Li P, Zhang J, Lu Z, Zeng Z. Static compression test and simulation analysis of honeycomb paperboard. Packaging Eng. 2010; 31(1): 34-37, 41 .

Received: May 15, 2015

Revised: June 23, 2015

Accepted: July 4, 2015

(C) Ju et al.; Licensee Bentham Open.

This is an open access articles licensed under the terms of the Creative Commons Attribution-Non-Commercial 4.0 International Public License (CC BY-NC 4.0) (https://creativecommons.org/licenses/by-nc/4.0/legalcode), which permits unrestricted, non-commercial use, distribution and reproduction in any medium, provided that the work is properly cited. 